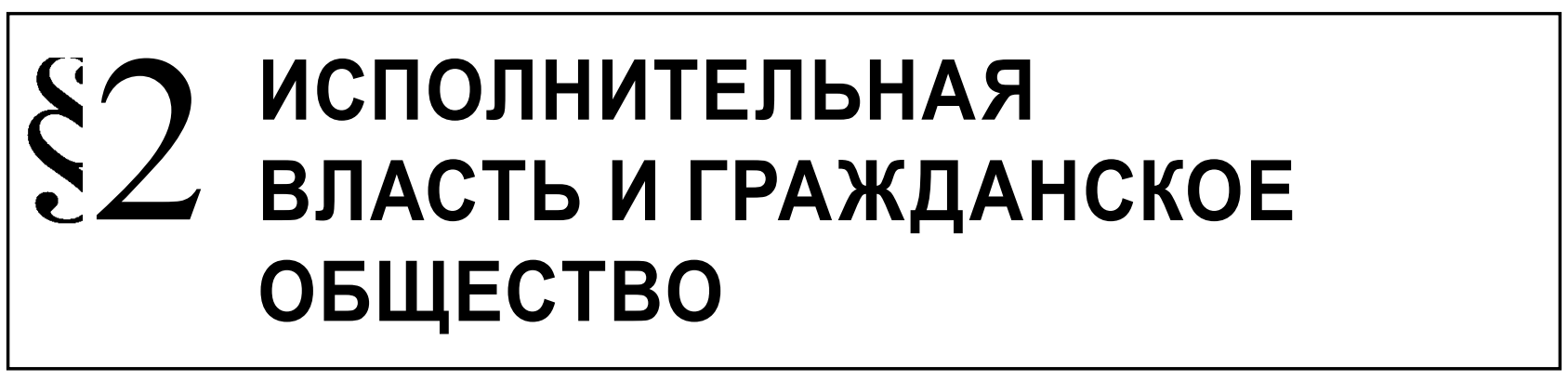

Грудцына Л.Ю.

\title{
ТЕОРИЯ КОНВЕРГЕНЦИИ ЧАСТНОПРАВОВЫХ И ПУБЛИЧНО-ПРАВОВЫХ НАЧАЛ В АСПЕКТЕ РАЗВИТИЯ ГРАЖДАНСКОГО ОБЩЕСТВА
}

Аннотация: Существование и развитие гражданского общества немыслимо вне сложной системы общественных отношений, и без участия (прямого или опосредованного) государства, в частности, посредством издания и применения норм частного и публичного права. Также влияние на гражданское общество оказывает политическая система государства, от качества которой в конкретный момент времени зависят модели развития общества. На первый взгляд, развитие гражданского общества происходит исключительно в рамках частных интересов, но участие публичной власти и распространение публичных норм на частноправовую среру (пусть, и опосредованным образом), нельзя подвергать сомнению. В развитых общественных системах частные и публичные отношения можно разграничить по признаку той автономии, которую государство определяет для своих граждан. Сфера отношений, отданных государством под господство граждан и исключающих вмешательство в них государства непосредственно, мы считаем отношениями частными. Это не означает, что государство самоустраняется от необходимого влияния на частные отношения, но оно не является главным и определяющим. Например, в срере религии государством провозглашена свобода вероисповедания. Однако государство ведет борьбу с тоталитарными и деструктивными сектами как исключительно вредным явлением для всего общества. любая правовая норма, устанавливающая частноправовые основы каких-либо общественных отношений, по сути и природе своей является публичной, хотя бы потому, что, во-первых, санкционируется государством и становится частью национального законодательства, во-вторых, не может противоречить и угрожать самой государственной системе и природе государственного управления. Более того, частноправовые и публично-правовые начала реализуются в тесной взаимосвязи с социально-экономическими и культурными отношениями в конкретный исторический отрезок времени, не могут быть оторванными от них, а потому - во многом логика их развития зависима от экономической ситуации, которая диктует, в частности, направление развития права и законодательства, а также судебного правоприменения и толкования законов. Экономические и культурные отношения, регулируемые правом, не принадлежат исключительно ни к одной из его областей и составляют общий предмет как публичного, так и частного права. Также несостоятельно разграничение права на частное и публичное при помощи интереса или характера общественных отношений, которые не составляют ни элементов правовой нормы, ни содержания субъективного права. Для целей нашего исследования представляет непосредственное значение, во-первых, взгляд Гегеля на гражданское общество как среру частных, единичных интересов, которая в определенных условиях приобретает самостоятельное значение по отношению к срере публичных (всеобщих) интересов. Во-вторых, вывод о том, что дирференциацию гражданского общества от государства (как сферы политической власти и управленческого аппарата) обеспечивают индивидуальные права граждан, ограждающие их от произвольного административного вмешательства и предоставляющие возможность воздействия на властные институты (поэтому индивидуальные права следует рассматривать как важный элемент структуры гражданского общества). B-третьих, указание на возможность достижения индивидуальной цели только «при соотношении с други- 
ми», то есть при наличии отношений солидарности, выступающей в качестве неотъемлемого элемента гражданского общества. Таким образом, согласно гегелевской концепции, сфера индивидуальных интересов, право и солидарность являются категориями, необходимыми для описания гражданского общества.Целью поддерживаемого государством гражданского мира является защита государством отдельного гражданина. Гражданин - это «естественная» единица или атом (хотя даже в условиях гражданства имеется определенный «конвенциональный» элемент). С другой стороны, членами или единицами (атомами) нашего международного порядка являются государства. Однако государство в принципе не может быть таким же "естественным" элементом, как гражданин: ведь не существует естественных границ государства, они меняются, и могут быть определены только посредством применения международного принципа status quо, а поскольку этот принцип всегда указывает на некоторую произвольно выбранную дату, то определение границ государства - чисто конвенциональная процедура.

Ключевые слова: государственное управление, гражданское общество, частное право, публичное право, государство, права человека, бизнес, экономика, закон, конвергенция права.

$\mathrm{B}$ понимании факторов, оказывающих влияние на развитие гражданского общества, следует учитывать не только конкретную историческую эпоху, но и предшествовавшее ей историческое развитие государства и общества. Кроме того, как верно указывал П.И. Новгородцев, необходимо помнить о различии практики и теории при сближении их друг с другом. Не всегда бывает возможно охарактеризовать практические отношения на основании теоретических идеалов, как невозможно и сводить все содержание этих идеалов к ближайшим практическим нуждам. ${ }^{1}$

Важной задачей, одновременно стоящей перед государством и обществом конкретной страны, является устранение «треугольника недоверия»: у государства - к обществу и бизнесу, у бизнеса к государству и обществу, у общества - к государству и бизнесу. ${ }^{2}$

На первый взгляд, развитие гражданского общества происходит исключительно в рамках частных интересов, но участие публичной власти и распространение публичных норм на частноправовую сферу (пусть, и опосредованным образом), нельзя подвергать сомнению. Как верно отметил Н.М. Коршунов, «частные и публичные интересы очень часто совпадают, и это делает их использование в качестве надежного критерия разграничения частного и публичного права весьма затруднительным». ${ }^{3}$

1 См.: Новгородцев П.И. Кант и Гегель в их учениях о праве и государстве. Два типических построения в области философии права. - М., 1901. - С. 27.

2 См.: Лагуткин А.В. Россия на распутье: куда пойдем? - М.: Юркомпани, 2013.

3 См.: Коршунов Н.М. Конвергенция частного и публичного права: проблемы теории и практики. - М.: Инфра-М, 2011. - C. 24.
С одной стороны, многие публично-правовые нормы, да и функции публичного права в целом в значительной мере направлены на защиту частных интересов. ${ }^{4}$ С другой стороны, любая правовая норма, устанавливающая частноправовые основы каких-либо общественных отношений, по сути и природе своей является публичной, хотя бы потому, что, во-первых, санкционируется государством и становится частью национального законодательства, во-вторых, не может противоречить и угрожать самой государственной системе и природе государственного управления.

Более того, частноправовые и публично-правовые начала реализуются в тесной взаимосвязи с социально-экономическими и культурными отношениями в конкретный исторический отрезок времени, не могут быть оторванными от них, а потому - во многом логика их развития зависима от экономической ситуации, которая диктует, в частности, направление развития права и законодательства, а также судебного правоприменения и толкования законов.

Экономические и культурные отношения, регулируемые правом, не принадлежат исключительно ни к одной из его областей и составляют общий предмет как публичного, так и частного права. Также несостоятельно разграничение права на частное и публичное при помощи интереса или характера общественных отношений, которые не составляют ни элементов правовой нормы, ни содержания субъективного права.

По мнению Н.М. Коршунова, «следует говорить о... формах сочетания публично-правового

\footnotetext{
4 См.: Покровский И.А. Основные проблемы гражданского права. - М., 2001. - С. 37; Тихомиров Ю.А. Публичное и частное право / Общая теория государства и права. Академический курс. - М., 2009. - С. 255.
} 
и частноправового регулирования общественных отношений, о конкретных границах публичного и частного права». Но как определить эти «конкретные» границы? И так ли уж необходимо их точное определение?

Ведь государство - многогранное явление, охватывающее не только сферу публичных интересов, но и «проникающее» во все пласты общественной жизни индивида. Например, жизнь гражданина в России будет отличаться от жизни местного населения в Германии, и разница будет не только в этнопсихологии, но и в сущности и модели существующей в странах политической и правовой систем.

Например, С.С. Алексеев пишет о том, что развитие правовых систем идет в основном в одном направлении: происходит взаимное обогащение права и в конченом счете своеобразная интеграция в праве, при которой правовые системы соединяются в целостные правовые образования, юридические конструкции. ${ }^{5}$ Такая конвергенция, отражающая закономерность развития национальных правовых систем, не ведет к нивелированию методов правового регулирования, поскольку никакого растворения частного права в публичном праве и наоборот, не происходит.

Вспомним Гегеля, у которого государство многоплановое явление, охватывающее различные сферы человеческой жизни, а не только аппаратно-управленческую и политическую. Обретение индивидом человеческого (нравственного) облика и объективация его как гражданина (в частности, законодательное наделение правами) возможны только в государстве. ${ }^{6}$ Соответственно, на наш взгляд, само наделение государством - с помощью принятия соответствующих законов - индивида правами и свободами, а также обязанностями уже является актом проявления публично-правовых начал, что не исключает, в то же время, частноправовой характер самих прав и свобод, которыми индивид наделяется. ${ }^{7}$

Гегель, разделяя государство и гражданское общество как сферу всеобщих и сферу частных интересов, настаивает на их органическом единстве

\footnotetext{
5 См.: Алексеев С.С. Линия права. - М.: Статут, 2006. - С. 114.

6 См.: Андрианов Н.В. Гражданское общество как среда институционализации адвокатуры. - М.: ЛИБРОКОМ, 2011. C. $35-36$.

7 См.: Грудцына Л.Ю. Гражданское общество и частное право // Международный академический журнал Российской академии естественных наук. 2013. № 4. С. 69-79.
}

и взаимопроникновении: «По отношению к сферам частного права и частного блага, семьи и гражданского общества, государство есть, с одной стороны, внешняя необходимость и их высшая власть, природе которой подчинены и от которой зависят их законы и их интересы; но, с другой стороны, оно есть их имманентная цель, и его сила в единстве его всеобщей конечной цели и особенного интереса индивидов, в том, что они в такой же степени имеют обязанности по отношению к нему, как обладают правами».

А. Грамши по-новому взглянул на государство, под которым понимал политическую общность (диктатуру или аппарат принуждения, призванный сформировать народную массу в соответствии со способом производства и экономикой данного момента), а не равновесие политической общности и общности гражданской, или гегемонию одной социальной группы над всей национальной общностью, ${ }^{8}$ осуществляемую через проводники институты гражданского общества (церковь, профсоюзы, образование и т.п.).

Кстати, интеллигенция очень часто действует именно в пределах гражданской общности. Например, А. Грамши писал о том, что подобная концепция «роли интеллигенции освещает причины или одну из причин падения средневековых коммун, т.е. правления экономического класса, который не смог создать собственной интеллигенции и, следовательно, осуществлять какую-либо гегемонию помимо диктатуры. ${ }^{9}$ Это очень важный постулат.

Для общества индивидов (точнее - граждан, о роли гражданства будет сказано ниже), государство есть, с одной стороны, внешняя необходимость и высшая (координирующая) власть, с другой стороны, оно есть их имманентная цель, и его сила в единстве его всеобщей конечной цели и особенного интереса индивидов. А именно: в том, что они в такой же степени имеют обязанности по отношению к нему, как обладают правами.

Но здесь же содержится указание на важный признак гражданского общества, а именно: наделение индивидов правами по отношению к государству, которое берет на себя соответствующие этим законным правам обязанности по их выполнению, гарантирует этот процесс.

\footnotetext{
8 См.: Грамши А. Искусство и политика. Письма Т. 1. - М.: Искусство, 1991. - С. 542.

9 См.: Грамши А. Искусство и политика. Письма Т. 1. - М.: Искусство, 1991. - С. 543.
} 
В этой связи, по мнению Н.В. Андрианова, «индивидуальные права, обеспечивающие как защиту от необоснованного административного вмешательства, так и возможность влиять на административный аппарат, следует рассматривать в качестве важного элемента структуры гражданского общества». ${ }^{10}$

По мнению Д.Л. Коэна и Э. Арато, Гегель к основным достижениям гражданского общества (современного ему немецкого буржуазного общества) относил «абстрактные права юридического лица и принцип субъективной свободы морального субъекта, намерения и воля которого должны быть приняты во внимание в любом суждении о действии». ${ }^{11}$

Гегель рассматривает государство как единый организм, целостную систему, не сводимую только к власти и тем более к управленческому аппарату. Вот что он прямо говорит по этому поводу: «Государство есть организм, т.е. развитие идеи в свои различия. Эти различенные стороны образуют различные власти, их функции и сферы деятельности, посредством которых всеобщее беспрестанно необходимым образом порождает себя, а поскольку оно именно в своем порождении предпослано, то и сохраняет себя. Этот организм есть политический строй: он вечно исходит из государства, так же как государство, в свою очередь, сохраняется благодаря ему; если оба они расходятся, если различенные стороны становятся свободными, то единство, которое их порождает, больше уже не положено. К ним применима басня о желудке и других частях тела. Природа организма такова, что если не все его части переходят в тождество, если одна из них полагает себя самостоятельной, то погибнуть должны все». ${ }^{12}$

Стоит отметить, что Гегель разделял три власти (не совпадающие с теорией разделения властей Монтескье): законодательную, правительственную (куда включал исполнительную и судебную власти в их современном понимании) и власть государя (верховную). «Этот организм есть политический строй: он вечно исходит из государства, так же как государство сохраняется благодаря ему... Природа организма такова, что если не все его части переходят в тождество, если одна из

\footnotetext{
10 См.: Андрианов Н.В. Гражданское общество как среда институционализации адвокатуры. - М.: ЛИБРОКОМ, 2011. C. 35-36.

11 См.: Коэн Джин Л., Арато Э. Указ. соч. С. 380.

12 См.: Гегель Г.В.Ф. Указ. соч. С. 287.
}

них полагает себя самостоятельной, то погибнуть должны все». ${ }^{13}$

Очевидно, что понятие государства для Гегеля шире понятий политической власти и государственного аппарата (политический строй). Из этого следует важный методологический вывод: при исследовании вопроса о соотнесении категории «государство» с иными научными категориями, в том числе с категорией «гражданское общество», желательно, во избежание двусмысленностей, в каждом конкретном случае расшифровывать понимание термина «государство». ${ }^{14}$ Приведенные положения гегелевской теории гражданского общества сохраняют важное методологическое значение и еще будут использованы в настоящей статье.

Но вернемся к гражданскому обществу. Прежде всего, любая интерпретация понятия «гражданское общество» предполагает соотнесение с понятием «государство», поскольку первое и исторически и в теоретическом анализе возникает лишь при наличии второго. При этом категория «государство» всегда требует от исследователя расшифровки: или под ним понимается система власти, или административный аппарат, или институционально организованное геополитическое пространство, или институционально организованное население, или все это вместе, объединенное «развитием идеи в ее различия». В противном случае приходится строить догадки по поводу сентенций в духе: «Гражданское общество призвано следить за государством». ${ }^{15}$ Кроме того, необходимо учитывать нетождественность понятий «общество» и «гражданское общество».

Итак, для целей нашего исследования представляет непосредственное значение, во-первых, взгляд Гегеля на гражданское общество как сферу частных, единичных интересов, которая в определенных условиях приобретает самостоятельное значение по отношению к сфере публичных (всеобщих) интересов.

Во-вторых, вывод о том, что дифференциацию гражданского общества от государства (как сферы политической власти и управленческого аппарата) обеспечивают индивидуальные права граждан,

\footnotetext{
13 См.: Гегель Г.В.Ф. Указ. соч. С. 293.

14 См.: Лагуткин А.В. Великая иллюзия демократии. - М.: Юркомпани, 2014.

15 Блестящий анализ гегелевской концепции гражданского общества содержится в работе классика отечественной теории государства и права П.И. Новгородцева. См.: Новгородцев П. И. Кант и Гегель в их учениях о праве и государстве. СПб., 2000. С. 330-351.
} 
ограждающие их от произвольного административного вмешательства и предоставляющие возможность воздействия на властные институты (поэтому индивидуальные права следует рассматривать как важный элемент структуры гражданского общества). ${ }^{16}$

В-третьих, указание на возможность достижения индивидуальной цели только «при соотношении с другими», то есть при наличии отношений солидарности, выступающей в качестве неотъемлемого элемента гражданского общества. Таким образом, согласно гегелевской концепции, сфера индивидуальных интересов, право и солидарность являются категориями, необходимыми для описания гражданского общества.

Целью поддерживаемого государством гражданского мира является защита государством отдельного гражданина. Гражданин - это «естественная» единица или атом (хотя даже в условиях гражданства имеется определенный «конвенциональный» элемент). С другой стороны, членами или единицами (атомами) нашего международного порядка являются государства. Однако государство в принципе не может быть таким же «естественным» элементом, как гражданин: ведь не существует естественных границ государства, они меняются, и могут быть определены только посредством применения международного принципа status quo, а поскольку этот принцип всегда указывает на некоторую произвольно выбранную дату, то определение границ государства - чисто конвенциональная процедура.

Отдельного рассмотрения требует учение $\mathrm{T}$. Парсонса о «социальной системе», под которой понимается общество, находящееся в «равновесии». Возможны небольшие колебания, но обычно общество пребывает в состоянии покоя. Все его части гармонично сочетаются друг с другом. Принадлежащие обществу индивиды обычно ориентируются на одни и те же нормы благодаря одинаковой для всех социализации. Они интегрированы в систему, следуют единым ценностям, без труда исполняют предписанные им роли. В нормальном состоянии конфликты между ними отсутствуют; изменения системы подобны помехам в работе отлаженного механизма. ${ }^{17}$

16 См.: Грудцына Л.Ю. Частная собственность и гражданское общество в России // Государство и право. 2008. № 6. C. 33-40.

17 См.: Грудцына Л.Ю. Общественная палата - спектакль национального масштаба // Адвокат. 2006. № 4.
Короче говоря, образ общества, получивший свое теоретическое выражение в понятии социальной системы, по мнению Н. Элиаса, при ближайшем рассмотрении оказывается идеальным образом нации. $^{18}$

Как пишет Г. Клаус, «мы хотим не только понимать общественные системы, но и владеть ими. Владеть, однако, не значит знать все причинные связи системы. При известных обстоятельствах достаточно уже знать закономерности ее поведения». ${ }^{19}$ Возьмем эту мысль на вооружение.

B.А. Энгельгардт полагал, что можно говорить о трех моментах, характеризующих взаимоотношения целого и части. Во-первых, это - возникновение взаимодействующей системы связей между частями целого. Во-вторых, утрата некоторых свойств части при вхождении в состав целого. В-третьих, появление у возникающей новой целостности новых свойств, обусловленных как свойствами основных частей, так и возникновением новых систем связей между частями. К этому нужно добавить еще упорядоченность частей, обусловленность их пространственного и функционального взаимоотношения. ${ }^{20}$

По мере возрастания целостности увеличивается и относительная независимость организма от среды, что связано с возникновением механизмов, позволяющих восстанавливать нарушение функций, вызванное изменениями в среде, сохранять в пределах нормы определенные, присущие организму параметры. ${ }^{21}$

Люди находятся в сети взаимозависимостей, которые прочно привязывают их друг к другу. Эта сеть может быть обозначена нами как фигурация определенная форма связи ориентированных друг на друга и взаимозависимых людей. Поскольку люди - сначала от природы, а затем и через обучение, воспитание, социализацию, социально пробуждаемые потребности - более или менее зависят друг от друга, постольку они всегда выступают во множественном числе, или, если можно так выразиться, существуют как «плюральности».

18 См.: Элиас Н. О процессе цивилизации. В 2-х томах. Том 1. - С. 38.

19 См.: Клаус Г. Кибернетика и общество / Пер. с нем. - М.: Прогресс, 1967. - С. 128.

20 См.: Энгельгардт В.А. Интегратизм - путь от простого к сложному в познании явлений жизни // Вопросы философии. 1970. № 11. С. 108.

21 См.: Афанасьев В.Г. Мир живого. Системность, эволюция и управление. Изд. 2-е. - М.: Издательств ЛКИ 2010. - С. 158. 
Они всегда предстают в тех или иных фигурациях (сообществах). Вот почему не слишком плодотворно понимание человека как одиночки. Куда более уместно исходить из картины множества взаимозависимых людей, образующих фигурации, группы или разного рода сообщества. Тем самым исчезает характерное для прежнего образа человека разделение на индивида (словно есть индивиды без общества) и общество (словно существует общество без людей). Понятие фигурации вводится нами именно потому, что своей ясностью оно превосходит понятийный инструментарий нынешней социологии.

Есть и другая теория. Как утверждает Б.В. Марков, государство «необходимости и рассудка» имеет своей предпосылкой существование эгоистичных автономных индивидов, не имеющих традиций и находящихся в злобно недоверчивых отношениях друг к другу. Но даже в США формирование политической воли достигалось, скорее, на основе морального признания, чем рационального договора. ${ }^{22}$

Ю. Хабермас видит следующий выход в интерсубъективном понимании процедуры народного суверенитета: место частноправовой модели договора между субъектами рынка занимает совещательная практика участников коммуникативного процесса. Формирование общественного мнения и политической воли осуществляется не только в форме компромиссов, но и по модели публичных дискурсов, нацеленных на рациональную приемлемость правил в свете общих интересов и ценностных ориентаций. ${ }^{23}$

Субъекты права - это не собственники самих себя и не солидарные частицы целого - народа, а индивиды, достигающие в процессе коммуникации нравственного признания друг друга, что и обеспечивает социальную интеграцию автономных индивидов. ${ }^{24}$

Однако там, где государство говорит своим гражданам, что отдает на их усмотрение и решение те или иные области общественных отношений, мы наблюдаем господство отношений частных. Это отношения политической самодеятельности партий и иных объединений, морали,

22 См.: Марков Б.В. Предисловие к книге Юргена Хабермаса «Вовлечение другого. Очерки политической теории». / Пер. с нем. Ю.С. Медведева. - СПб.: Наука, 2001.

23 См.: Грудцына Л.Ю. Гражданское общество и частное право // Новый юридический журнал. 2013. № 2. С. 79-89.

24 См.: Марков Б.В. Там же. свободы мысли, значительная часть экономических отношений, образования, науки, культуры, спорта и т.д. ${ }^{25}$

Ходом исторического развития современной России и в силу складывающихся обстоятельств внутри частных отношений наметились появления так называемых пограничных отношений, еще недавно позиционируемых в качестве публичных. Таковы, например, финансовые, земельные, медицинские, образовательные, природоресурсные, неимущественные (в границах гражданского права) отношения в области оказания услуг и прав человека. Эти примеры можно умножить, но их достаточно, чтобы констатировать наличие сложной общественной проблемы. ${ }^{26}$

Если обратиться к финансовым отношениям, то можно увидеть их неоднородность. Например, в СССР все финансы (начиная с реформы 1930 г.) были предметом публичных отношений и находились в сфере государственного ведения. Однако затем положение стало меняться, мы стали свидетелями образования большой банковской системы, подчиняющейся частному регулированию. Дело не ограничилось только банками; частными становились ломбарды, страхование (его финансовая составляющая), общества взаимного кредитования, создаваемые как кооперативы, часть инвестиционных программ и т.д. ${ }^{27}$

По мнению Н. Элиаса, «наиболее полная интеграция всех граждан со своим государством в условиях европейской многопартийности осуществилась только лишь в XX веке». ${ }^{28}$ Осознанное отождествление граждан себя даже с государством является фактом относительно недавнего времени. ${ }^{29}$

В развитых общественных системах частные и публичные отношения можно разграничить по признаку той автономии, которую государство определяет для своих граждан. Сфера отношений, отданных государством под господство граждан

25 См.: Иванов В.И. Частные отношения: постановка вопроса // Образование и право. № 5(21). - С. 51.

26 См.: Иванов В.И. Частные отношения: постановка вопроса // Образование и право. № 5(21). - С. 51.

27 См.: Лагуткин А.В., Грудцына Л.Ю. Гражданское общество в современной России: проблемы роста // Представительная власть - XXI век: законодательство, комментарии, проблемы. 2013. № 2-3. С. 6-10.

28 См.: Элиас Н. Общество индивидов. - М., 2001. - С. 289.

29 См.: Андрианов Н.В. Гражданское общество как среда институционализации адвокатуры. - М.: ЛИБРОКОМ, 2011. C. 48 . 
и исключающих вмешательство в них государства непосредственно, мы считаем отношениями частными. Это не означает, что государство самоустраняется от необходимого влияния на частные отношения, но оно не является главным и опреде- ляющим. Например, в сфере религии государством провозглашена свобода вероисповедания. Однако государство ведет борьбу с тоталитарными и деструктивными сектами как исключительно вредным явлением для всего общества.

\section{Библиография}

1. Алексеев С.С. Линия права. - М.: Статут, 2006. - С. 114.

2. Андрианов Н.В. Гражданское общество как среда институционализации адвокатуры. - М.: ЛИБРОКОМ, 2011. - С. 35-36.

3. Афанасьев В.Г. Мир живого. Системность, эволюция и управление. Изд. 2-е. - М.: Издательств ЛКИ 2010. - C. 158.

4. Грамши А. Искусство и политика. Письма Т. 1. - М.: Искусство, 1991. - С. 542.

5. Грудцына Л.Ю. Гражданское общество и частное право // Международный академический журнал Российской академии естественных наук. 2013. № 4. С. 69-79.

6. Грудцына Л.Ю. Гражданское общество и частное право // Новый юридический журнал. 2013. № 2. С. 79-89.

7. Грудцына Л.Ю. Общественная палата-спектакль национального масштаба // Адвокат. 2006. № 4.

8. Грудцына Л.Ю. Частная собственность и гражданское общество в России // Государство и право. 2008. № 6. С. 33-40.

9. Иванов В.И. Частные отношения: постановка вопроса // Образование и право. № 5(21). - С. 51.

10. К Клаус Г. Кибернетика и общество / Пер. с нем. - М.: Прогресс, 1967. - С. 128.

11. Коршунов Н.М. Конвергенция частного и публичного права: проблемы теории и практики. - М.: Инфра-М, 2011. - С. 24.

12. Лагуткин А.В. Великая иллюзия демократии. - М.: Юркомпани, 2014.

13. Лагуткин А.В. Россия на распутье: куда пойдем?-М.: Юркомпани, 2013.

14. Лагуткин А.В., Грудцына Л.Ю. Гражданское общество в современной России: проблемы роста // Представительная власть-ХХІ век: законодательство, комментарии, проблемы. 2013. № 2-3. С. 6-10.

15. Марков Б.В. Предисловие к книге Юргена Хабермаса «Вовлечение другого. Очерки политической теории». / Пер. с нем. Ю.С. Медведева. - СПб.: Наука, 2001.

16. Новгородцев П.И. Кант и Гегель в их учениях о праве и государстве. Два типических построения в области философии права. - М., 1901. - С. 27.

17. Покровский И.А. Основные проблемы гражданского права. - М., 2001. - С. 37; Тихомиров Ю.А. Публичное и частное право / Общая теория государства и права. Академический курс. - М., 2009. - С. 255.

18. Элиас Н. О процессе цивилизации. В 2-х томах. Том 1. - С. 38.

19. Элиас Н. Общество индивидов. - М., 2001. - С. 289.

20. Энгельгардт В.А. Интегратизм - путь от простого к сложному в познании явлений жизни // Вопросы философии. 1970. № 11. С. 108.

21. Грудцына Л.Ю Развитие гражданского общества в аспекте конвергенции частно-правовых и публично-правовых начал российского права // Административное и муниципальное право. - 2013. - 5. C. 404-409. DOI: 10.7256/1999-2807.2013.05.2.

22. Грудцына Л.Ю., Петров С.М. Власть и гражданское общество в России: взаимодействие и противо- стояние // Административное и муниципальное право. - 2012. - 1. - С. 19-29.

23. Борисенков А.A. Современная российская конституция о власти // NB: Вопросы права и политики. - 2014. - 1. - С. 19-44. DOI: 10.7256/2305-9699.2014.1.10585. URL: http://www.e-notabene.ru/lr/ article_10585.html

24. Борисенков A.A. Политическая власть - политическая субстанция // NB: Проблемы общества и политики. - 2013. - 6. - С. 193-217. DOI: 10.7256/2306-0158.2013.6.806. URL: http://www.e-notabene.ru/ pr/article_806.html

25. Кодан С.В. СИСТЕМА ЗАКОНОДАТЕЛЬСТВА В РОССИИ: ФОРМИРОВАНИЕ, РАЗВИТИЕ, СТАНОВЛЕНИЕ (IX - начало XX вв.) // NB: Проблемы общества и политики. - 2013. - 4. - C. 239-293. DOI: 10.7256/23060158.2013.4.436. URL: http://www.e-notabene.ru/pr/article_436.html 
26. Знаменский Д.Ю. Государство и гражданское общество в процессе формирования приоритетов государственной научно-технической политики // NB: Проблемы общества и политики. - 2013. - 10. C. 1-17. DOI: 10.7256/2306-0158.2013.10.9489. URL: http://www.e-notabene.ru/pr/article_9489.html

27. Уваров А.А. О роли государства в формировании гражданского общества // NB: Вопросы права и политики. - 2013. - 7. - С. 1-40. DOI: 10.7256/2305-9699.2013.7.8782. URL: http://www.e-notabene.ru/lr/ article_8782.html

28. ЗаЙЦеВ А.В. ИНСТИТУЦИОНАЛЬНЫЙ ДИАЛОГ В СФЕРЕ КОММУНИКАЦИИ ГОСУДАРСТВА И ГРАЖДАНСКОГО ОБЩЕСТВА: ТЕОРЕТИКО-МЕТОДОЛОГИЧЕСКИЙ ПОДХОД // NB: ПроблемЫ общества и политики. - 2012. - 1. - C. 21-54. URL: http://www.e-notabene.ru/pr/article_110.html

29. Щупленков О.В., Щупленков Н.О. Проблемы взаимодействия гражданского общества и государства в современной России // NB: Вопросы права и политики. - 2013. - 4. - C. 1-55. DOI: 10.7256/23059699.2013.4.585. URL: http://www.e-notabene.ru/lr/article_585.html

30. А.С. Емельянов Административно-правовая доктрина, идеи либерализма и развитие государственности в России // Политика и Общество. - 2013. - 2. - C. 220-225. DOI: 10.7256/1812-8696.2013.02.13.

31. ЗаЙцев А.В. ДИАЛОГ ГОСУДАРСТВА И ГРАЖДАНСКОГО ОБЩЕСТВА КАК ПЕРЕГОВОРНЫЙ ПРОЦЕСС: ЛИНГВО-ПОЛИТОЛОГИЧЕСКИЙ АСПЕКТ. // NB: Проблемы общества и политики. - 2012. - 3. - С. 34-47. URL: http://www.e-notabene.ru/pr/article_120.html

32. В.Н. Шеломенцев Формирование законодательства о гражданском обществе в России на рубеже XVIII--XIX веков // Политика и Общество. - 2013. - 1. - С. 4-16. DOI: 10.7256/1812-8696.2013.01.1.

\section{References}

1. Alekseev S.S. Liniya prava. - M.: Statut, 2006. - S. 114.

2. Andrianov N.V. Grazhdanskoe obshchestvo kak sreda institutsionalizatsii advokatury. - M.: LIBROKOM, 2011. - S. 35-36.

3. Afanas'ev V.G. Mir zhivogo. Sistemnost', evolyutsiya i upravlenie. Izd. 2-e. - M.: Izdatel'stv LKI 2010. - S. 158.

4. Gramshi A. Iskusstvo i politika. Pis'ma T. 1. - M.: Iskusstvo, 1991. - S. 542.

5. Grudtsyna L.Yu. Grazhdanskoe obshchestvo i chastnoe pravo // Mezhdunarodnyi akademicheskii zhurnal Rossiiskoi akademii estestvennykh nauk. 2013. № 4. S. 69-79.

6. Grudtsyna L.Yu. Grazhdanskoe obshchestvo i chastnoe pravo // Novyi yuridicheskii zhurnal. 2013. № 2. S. 79-89.

7. Grudtsyna L.Yu. Obshchestvennaya palata-spektakl' natsional'nogo masshtaba // Advokat. 2006. № 4.

8. Grudtsyna L.Yu. Chastnaya sobstvennost' i grazhdanskoe obshchestvo v Rossii // Gosudarstvo i pravo. 2008. № 6. S. 33-40.

9. Ivanov V.I. Chastnye otnosheniya: postanovka voprosa // Obrazovanie i pravo. № 5(21). - S. 51.

10. Klaus G. Kibernetika i obshchestvo / Per. s nem. - M.: Progress, 1967. - S. 128.

11. Korshunov N.M. Konvergentsiya chastnogo i publichnogo prava: problemy teorii i praktiki. - M.: Infra-M, 2011. - S. 24.

12. Lagutkin A.V. Velikaya illyuziya demokratii. - M.: Yurkompani, 2014.

13. Lagutkin A.V. Rossiya na rasput'e: kuda poidem?-M.: Yurkompani, 2013.

14. Lagutkin A.V., Grudtsyna L.Yu. Grazhdanskoe obshchestvo v sovremennoi Rossii: problemy rosta // Predstavitel'naya vlast'-XXI vek: zakonodatel’stvo, kommentarii, problemy. 2013. № 2-3. S. 6-10.

15. Markov B.V. Predislovie k knige Yurgena Khabermasa «Vovlechenie drugogo. Ocherki politicheskoi teorii». / Per. s nem. Yu.S. Medvedeva. - SPb.: Nauka, 2001.

16. Novgorodtsev P.I. Kant i Gegel' v ikh ucheniyakh o prave i gosudarstve. Dva tipicheskikh postroeniya v oblasti filosofii prava. - M., 1901. - S. 27.

17. Pokrovskii I.A. Osnovnye problemy grazhdanskogo prava. - M., 2001. - S. 37; Tikhomirov Yu.A. Publichnoe i chastnoe pravo / Obshchaya teoriya gosudarstva i prava. Akademicheskii kurs. - M., 2009. - S. 255.

18. Elias N. O protsesse tsivilizatsii. V 2-kh tomakh. Tom 1. - S. 38.

19. Elias N. Obshchestvo individov. - M., 2001. - S. 289.

20. Engel'gardt V.A. Integratizm - put' ot prostogo k slozhnomu v poznanii yavlenii zhizni // Voprosy filosofii. 1970. № 11. S. 108. 
21. Grudtsyna L.Yu Razvitie grazhdanskogo obshchestva v aspekte konvergentsii chastno-pravovykh i publichnopravovykh nachal rossiiskogo prava // Administrativnoe i munitsipal'noe pravo. - 2013. - 5. - C. 404-409. DOI: 10.7256/1999-2807.2013.05.2.

22. Grudtsyna L.Yu., Petrov S.M. Vlast' i grazhdanskoe obshchestvo v Rossii: vzaimodeistvie i protivo- stoyanie // Administrativnoe i munitsipal'noe pravo. - 2012. - 1. - C. 19-29.

23. Borisenkov A.A. Sovremennaya rossiiskaya konstitutsiya o vlasti // NB: Voprosy prava i politiki. - 2014. - 1. C. 19-44. DOI: 10.7256/2305-9699.2014.1.10585. URL: http://www.e-notabene.ru/lr/article_10585.html

24. Borisenkov A.A. Politicheskaya vlast' - politicheskaya substantsiya // NB: Problemy obshchestva i politiki. 2013. - 6. - C. 193-217. DOI: 10.7256/2306-0158.2013.6.806. URL: http://www.e-notabene.ru/pr/ article_806.html

25. Kodan S.V. SISTEMA ZAKONODATEL"STVA V ROSSII: FORMIROVANIE, RAZVITIE, STANOVLENIE (IX - nachalo XX vv.) // NB: Problemy obshchestva i politiki. - 2013. - 4. - C. 239-293. DOI: 10.7256/2306-0158.2013.4.436. URL: http://www.e-notabene.ru/pr/article_436.html

26. Znamenskii D.Yu. Gosudarstvo i grazhdanskoe obshchestvo $\mathrm{v}$ protsesse formirovaniya prioritetov gosudarstvennoi nauchno-tekhnicheskoi politiki // NB: Problemy obshchestva i politiki. - 2013. - 10. S. 1-17. DOI: 10.7256/2306-0158.2013.10.9489. URL: http://www.e-notabene.ru/pr/article_9489.html

27. Uvarov A.A. O roli gosudarstva $v$ formirovanii grazhdanskogo obshchestva // NB: Voprosy prava i politiki. 2013. - 7. -S. 1-40. DOI: 10.7256/2305-9699.2013.7.8782.URL: http://www.e-notabene.ru/lr/article_8782. html

28. Zaitsev A.V. INSTITUTsIONAL"NYI DIALOG V SFERE KOMMUNIKATsII GOSUDARSTVA I GRAZhDANSKOGO OBShchESTVA: TEORETIKO-METODOLOGIChESKII PODKhOD // NB: Problemy obshchestva i politiki. 2012. - 1. - S. 21-54. URL: http://www.e-notabene.ru/pr/article_110.html

29. Shchuplenkov O.V., Shchuplenkov N.O. Problemy vzaimodeistviya grazhdanskogo obshchestva i gosudarstva v sovremennoi Rossii // NB: Voprosy prava i politiki. - 2013. -4.-S. 1-55. DOI: 10.7256/2305-9699.2013.4.585. URL: http://www.e-notabene.ru/lr/article_585.html

30. A.S. Emel'yanov Administrativno-pravovaya doktrina, idei liberalizma i razvitie gosudarstvennosti v Rossii // Politika i Obshchestvo. - 2013. - 2. - S. 220-225. DOI: 10.7256/1812-8696.2013.02.13.

31. Zaitsev A.V. DIALOG GOSUDARSTVA I GRAZhDANSKOGO OBShchESTVA KAK PEREGOVORNYI PROTsESS: LINGVO-POLITOLOGIChESKII ASPEKT. // NB: Problemy obshchestva i politiki. - 2012. - 3. - S. 34-47. URL: http://www.e-notabene.ru/pr/article_120.html

32. V.N. Shelomentsev Formirovanie zakonodatel'stva o grazhdanskom obshchestve v Rossii na rubezhe XVIII-XIX vekov // Politika i Obshchestvo. - 2013. - 1. - S. 4-16. DOI: 10.7256/1812-8696.2013.01.1. 